\title{
THE MERCURY MINERALS FROM TERLINGUA, TEXAS: KLEINITE, TERLINGUAITE, EGLESTONITE, MONTROYDITE, CALOMEL, MERCURY.
}

W. KE, HILLEBRANI AXL W, 'Y SCHALLER.

In the late fall of 1905 the senior author received for identification from Mr. H. W. Turner, at that time connected with one of the mining companies of Terlingua, Texas, specimens of two minerals from the well known Terlingua mercury field in Brewster county. One of these proved to be the unidentified mineral referred to as Yo. 5 by Professor A. J. Moses in his paper" on new mercury minerals from that district, namely terlinguaite, eglestonite and montroydite, the last of these being mercuric oxide, the others oxychlorides. Preliminary tests having shown that No. 5 belonged to the so-called mercury-ammonium compouuds, hitherto nnknown in nature, a brief announcement" of this fact was made in order to secure the field for as full an investigation of this unique mineral and its associates as the material on hand and to be obtained might permit.

This work has been conducted at intervals during the past eighteen months, and is yet incomplete with reference to the new mineral. It has, however, extended over so long a time and the chances for obtaining more perfect material than that already arailable are so slight, that it is deemed inadvisable to longer delay publication of the results obtained. The full details of the work herein summarized will be found in a bulletin of the U. S. Geological Survey, the appearance of which will unfortunately be delayed still longer, chiefly on account of the plates that are to illustrate it and the unavoidable delays attending publication. Although the present condensation reproduces the essential points as to the chemistry of the minerals, it but touches their crystallographical side, which, though of much interest for the great number of forms shown by most of the minerals, requires too extended treatment for a resume of this character. Further, many observations of interest that cannot be detailed here were made, upon which some of the conclusions were based, particularly in studying kleinite the mercury-ammonium compound. For these as well as the details of crystallography and association reference must be made to the full report.

A few words, however, with reference to their association as observed by us ate necessary in this place. The minerals are deposited on a matrix of two kinds, first a soft, siliceous-aluminous, earthy mass, sometimes gray but usually of a pinkish color and containing a small amount

1 Condensed from a fortlicoming bulletin of the $L$. S. Geological Survey. Chenistry by Hillebrand, crystallography, etc, by Schaller.

Am. J. Sci., [t] 16, 253 (1903).

Science, 22, S44 (1905); J. Am, Cliem. Soc, 28, r22 (1906); Am. J. Sci. [4], $21,85(1906)$. 
of calcium carbonate, and second, a fairly pure layer of calcite with large scalenohedral crystals projecting from the surface. The general associations of the several minerals are given below, but there are many exceptions that will be noted in the full report. Kleinite is found with gypsum, calcite, seldom with barite and calomel, either loose or on a whitish, clayey gangue, only once or twice accompanied by terlinguaite; calomel with calcite, mercury and eglestonite on the pinkish earthy gangue; eglestonite with calomel, calcite and mercury on the pink gangue or on calomel; montroydite with calcite, terlinguaite, and mercury on the calcite layer; terlinguaite with calcite, montroydite and mercury on the calcite layer.

Several members of this group of minerals are characterized by a most unusual property, namely, proneness to change color rapidly on exposure to light. With respect to terlinguaite and eglestonite this change is of a permanent character, and the result is to impart to the minerals an appearance often quite different from that they originally possessed. With kleinite the change is not to a different color but only to a different shade, and it persists only as long as the expostre itself, the original color returning in the dark. From published and privately communicated statements it would seem as if these minerals, in their earthy forms at least, must be difficult to distinguish as a rule when first found, by reason of the similarity of their original colors, all more or less pronouncedly yellow.

In addition to the specimens first received from Mr. Turner, many fine ones were donated by Mr. J. H. Hartley, who was also connected with one of the Terlingua mining companies, and later Mr. R. M. Wilke, of Berkeley, California, gave kleinite when more was needed. All was, so far as known to us, from the properties of the Marfa and Mariposa Mining Co., and chiefly from the Terceiro shaft. Professor A. J. Moses kindly identified the new mineral with his No. 5, and sent us his original measurements of the latter. To these gentlemen, and especially to Mr. Hartley for his most generous liberality, also to Dr. P. G. Nutting, of the Bureau of Standards, and Prof. B. B. Boltwood, of New Haven, who kindly made certain tests, we take occasion to express our deep sense of obligation.

In the several descriptions that foliow we have incorporated data already correctly given by Professors Moses and Sachs, as well as the new matter gathered by ourselves, in order to present as complete a record as possible of the minerals described. In general due recognition is given of observations made by others, though it may not have been possible in every case.

Kleinite.

Before describing the unique compound referred to in the foregoing it 
will be necessary to impose on the reader a little history. On the day preceding the appearance in Science of the announcement regarding the new mercury-ammonium compound there was read at a meeting of the Royal Prussian Academy of Sciences a paper by Professor A. Sachs, of Breslau, descriptive of an oxychloride of mercury which was regarded by him as perhaps identical with the No. 5 of Professor Moses, and to which he assigned the formula $\mathrm{Hg}_{4} \mathrm{Cl}_{2} \mathrm{O}_{3}$, or $3 \mathrm{HgO} . \mathrm{HgCl}_{2}$, and the name kleinite, after the eminent mineralogist Prof. Carl Klein. This paper appeared in print ${ }^{1}$ on Jan. I I, I906. After reading the announcement of the mercury-ammonium mineral, said to be also identical with the above No. 5 of Professor Moses, Professor Sachs made new analyses of material in his possession and obtained results ${ }^{2}$ agreeing qualitatively in each case and quantitatively in one with those which had already been obtained in Washington. His later data appear in the table below:

\begin{tabular}{|c|c|c|c|}
\hline \multicolumn{3}{|c|}{ Sulphur-yellow Crystals } & Orange Crystals \\
\hline $\mathrm{H}_{g} \ldots \ldots \ldots \ldots \ldots \ldots \ldots \ldots$ & & & 85.29 \\
\hline$c 1 \ldots \ldots \ldots \ldots \ldots \ldots \ldots \ldots$ & & & 6.97 \\
\hline $\mathrm{SO}_{3} \ldots \ldots \ldots \ldots \ldots \ldots$ & 1.05 & 0.85 & 2.57 \\
\hline $\mathrm{NH}_{3} \ldots \ldots \ldots \ldots \ldots \ldots \ldots$ & 0.44 & 1.09 & 2.79 \\
\hline
\end{tabular}

He regarded the sulphur-yellow crystals as the purer, and from the varying values for sulphur and nitrogen argued that these could not be integral components of the mineral. Without conmitting himself to any view as to the molecular arrangement, the following formula was suggested as the most plausible $-\mathrm{Hg}_{4}\left(\mathrm{Cl} .1 / 2 \mathrm{SO}_{4}\right)_{2}\left[\mathrm{O},\left(\mathrm{NH}_{2}\right)_{2}\right]_{3}$ - which is of the same type as his original oxychloride, $\mathrm{Hg}_{4} \mathrm{Cl}_{2} \mathrm{O}_{3}$, but is far from being in close agreement with his analytical data and is also opposed to the chemical behavior of the mineral as a mercury-ammonium compound. The assumption by Professor Sachs of hydrogen, and of oxygen other than that in the $\mathrm{SO}_{4}$ radicle, was purely arbitrary, and it may be said here that his surmises as to the formula of the mineral have not been verified by the results of our work, nor have we found any certain difference in composition between the light yellow and the orange crystals.

It had been the intention of the senior author to assign to the mineral a name indicative in some manner of its composition when this should have been fully established, but to now substitute for the name kleinite, already in the literature even though applied to an incorrectly identified species, another name, no matter how appropriate, would occasion confusion that it is desirable to avoid; hence the name kleinite is accepted without reserve.

Physical Properties. Most of the material as received was in loose crystals or crystal aggregates, to which adhered more or less of a dull eurthy white to reddish foreign matter of a clay-like character. While

1 Sitzb. kgl. Preuss. Akad. Wiss,, 1905, Iog1-I094.

2 Centralb. Min. Geol. Pal., 1906, 200-202. 
many of the crystals were very fine and brilliant much of the material was far too impure for the chemical tests that were contemplated. Even the selected crystals and aggregates held here and there a little of the gangue firmly attached and some must also be included in the crystals themselves in an extraordinarily fine state of division, to judge both from microscopic evidence and from the amount of non-volatile matter that was left on ignition, which ranged from about 0.75 to nearly 3 per cent. This gangue interfered much with the correct determination of the water given off by the mercury mineral on heating and hence with the establishment of a formula.

A peculiarity not noticed by other observers is that when exposed to sunlight or even to the diffused light of a room, after having been in the dark, the crystals, at first canary yellow, almost immediately became nuch deeper in color, generally reddish yellow or orange, but that they regained their original color very soon when again placed in the dark. This phenomenon could be reproduced as often as desired. It was also noticed that the exposed crystals were not all of the same shade of yellow; there were some that had not changed at all and others that showed all gradations between almost colorless and orange, and one crystal was seen with an orange core and a light outer zone. Professor Sachs also noticed different shades in the same crystal. In powder the color is sulphuryellow. One of the first specimens received was composed entirely of very pale yellow, coherent crystal masses held together by or holding together a reddish earthy gangue. The lighter crystals that were picked out for separate analysis from samples of the loose crystals varied in color, but all were much lighter than the rest in daylight.

The density was determined on several specimens and found to average for the orange crystals 7.975 and for the light yellow 7.987 , but the results are all low because of the attached or included earthy matter. These figures are much higher than the 7.44 I given by Sachs. The crystal form is hexagonal ; $c=1.6642$ (mean of Schaller's and Sachs' values). The habit is short prismatic, rarely equidimensional. (Fig. I.)
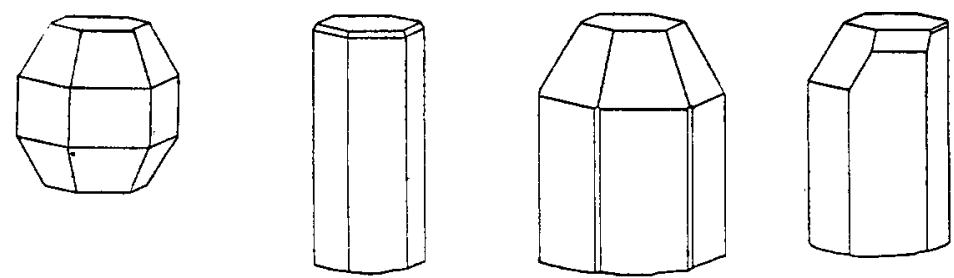

FIG. I.-Crystals of Kleinite Showing Variation in Habit.

Single crystals rarely exceed one millimeter in length, but masses of crystalline material may exceed one centinseter. Five forms 
have been observed namely, $c\{000 \mathrm{I}\}, m\{$ IOIO $\}, a\{\operatorname{II} 20\}, p\{$ IOII $\}$ and $x\{1012\}$ (new). Cleavage is good parallel to $\{000 \mathrm{I}\}$ and imperfect parallel to $\{1010\}$. Brittle. Luster adamantive to greasy on bright surfaces. Hardness apparently slightly over 3.5. Not radioactive (Boltwood), but Nutting reported faint evidence of helium on first warming the mineral in a vacuum.

The mineral being geometrically hexagonal a basal section should remain dark under crossed nicols. But, as described by Moses, such a section does not remain dark but shows double refraction and if thin enough will be seen to be composed of innumerable individuals, none of which is large enough to show interference figures. The double refraction is strong, the colors being of the third and higher orders. At about $130^{\circ}$ the double refraction begins to decrease, as seen by the descending colors, until finally it becomes zero and the mineral remains clark under crossed nicols. The section now gives a uniaxial, positive interference figure. After cooling, the section remains dark but after the lapse of many months is seen to be slowly returning to its doubly refracting condition. This phenomenon seems to show that kleinite is dimorphous and that the uniaxial optical state agreeing with its outward hexagonal form is stable only above $130^{\circ}$ approximately, while below that temperature its stable condition is biaxial, probably triclinic. According to this the hexagonal crystals of kleinite must have been formed at a temperature not much if any below $130^{\circ}$. As is stated just below, it is at a point but a few degrees higher than this that the first permanent browning of the mineral becomes visible when it is heated, and that considerable loss of water has then taken place. What connection, if any, there may be between these two phenomena is not known.

Pyrognostic Behavior. When carefully heated in a closed tube, or better in one throngh which passes a slow current of air, the mineral loses a little water, begins to brown at $135^{\circ}-150^{\circ}$, and as the temperature rises becomes still darker and yields more water, but gives no visible sublimate under $260^{\circ}$ even after several hours. Between $260^{\circ}$ and $280^{\circ}$ mercury and calomel (not $\mathrm{HgCl}_{2}$ ) sublime. When most of the calomel has passed off the residue begins to grow lighter colored, then yellowish and finally becomes nearly white. During the expulsion of the calomel some gas ( $\mathrm{Cl}$ ?) is evolved in minute amount that sets free iodine from solution of potassinm iodicle. On heating to $400^{\circ}$ more of this active gas is evolved, but it is soon followed or accompanied by one that destroys the color of the free iodine $\left(\mathrm{SO}_{2}\right.$ ? ). At $400^{\circ}-420^{\circ}$ appears a further sublimate less volatile than the calomel. If the test is made in a closed assay tube this last sublimate and the still unvolatilized residue may melt to a dark reddish liquid, which on cooling 
solidifies with a yellowish and then white color. Ammonia turns both sublimates black instantaneously, although the latter one often contains mercuric as well as mercurous sulphate. Most of the nitrogen escapes in the elemental state during the formation of the calomel, but not quite all. There is not the least evidence of the formation of ammonia. If the heating is carried out in vacuo the evolution of the active gas is much more marked than at atmospheric pressure and if collected by a pump is seen to be of the color of chlorine. Under the vacuum this gas does not act on the mercury of the pump, but fouls that in the collecting tube strongly under atmospheric pressure. The scum on the mercury gives tests for chlorine. This liberation of free chlorine was at first supposed to indicate direct union of nitrogen and chlorine in the mineral, but since it is also given off on heating in vacuo a mixture of the artificial compound $\mathrm{NHg}_{2} \mathrm{Cl} . x \mathrm{H}_{2} \mathrm{O}$ with a sulphate of mercury $\left(3 \mathrm{HgO} . \mathrm{SO}_{3}\right.$ in the test) it is evidently a secondary reaction between one of the products of breaking up of the radicle $\mathrm{SO}_{4}$ and vapor of calomel or of the still undecomposed chlorine constituent of the mineral.

Behavior Toward Liquid Reagents. Soluble in warm hydrochloric as well as nitric acid without deposition of calomel. Also soluble in sodium sulphide and in ammonium bromide. The latter liberates as ammonia for every one part of nitrogen derived from the mineral itself three parts from the reagent. Fixed alkalies do not liberate ammonia. Hydrogen sulphide blackens speedily, ammonia not at all.

Additional Data. Several tests were made by decomposing the mineral in vacuo under varying conditions of treatment in order to get evidence as to the presence of either hydrogen in addition to that which ras afforded as water or of oxygen other than that in water and the $\mathrm{SO}_{4}$ radicle. For the evidence on these points reference must be made to the full report; suffice it to say here that no certain evidence was obtained in favor of the presence of one or the other of these elements other than in the combinations above named, though the proof is not absolute that there may not be small amounts of one or both (See also p. II88). If present, the hydrogen is in such small amount as to be unimportant in the formula of the mineral as a homogeneous unit, and oxygen must also exist in all probability as basic oxygen in a minor constituent of a mixture. The summation given on $p$. I 88 is a strong argument against the presence of considerable percentages of either.

When, however, the mineral is fully decomposed by heat in presence of line or sodium carbonate oxygen is liberated in quantity. Theoretically the amount should be exactly equivalent to the $\mathrm{SO}_{4}$ and $\mathrm{Cl}_{2}$ found in a particular sample if the compound is normal and not basic, and this should afford an exact means for deciding the question of the presence of oxygen. But as a matter of fact the oxygen never did equal the 
calculated amount by several tenths of one per cent. Of the various possible explanations to account for the deficiency the following, based partly on qualitative tests, seems the most probable. The oxygen is liberated partly in an active state, and forms a chloroxy-salt of sodium or else nitrite or nitrate of sodium in small amount. It would require but little of one of these salts to bind enough oxygen to account for the observed deficiency. The evidence favors an oxy-salt of nitrogen in preference to one of chlorine. It is, of course, assumed that any such salt was formed by the act of decomposition and did not pre-exist in the mineral.

Analytical Methods Employed and the Results. - (I) Nitrogen. For nitrogen three methods were used: $(a)$ expulsion as ammonia by sodium sulphide and gravimetric determination as the chlorplatinic salt; $(b)$ expulsion as ammonia by ammonium bromide in a closed vessel, collection of the ammonia in titrated oxalic acid and determination of the acid left over; (c) direct determination as nitrogen gas expelled in vacuo, collected by the aid of a Töpler pump, and measured in a gas burette after freeing from other gases if present.

Numerous data are to be found in the full report relating to these methods, particularly the last. The second method was found to yield about two-tenths per cent. more nitrogen than the first or than the second, when sodium carbonate was used as a retainer for the chlorine and sulphur, the results by which agreed well. This was probably in part if not altogether due to the action of the clayer gangue on the ammonium bromide with liberation of some ammonia (see p. I188). Were it not for this effect of the gangue the method wonld be an excellent one for obtaining proof as to the presence or absence of basic oxygen. The nitrogen found by the third method was finally tested by passing it over hot magnesium, which absorbed apparently the whole of it. It was also tested spectroscopically. The analytical results were as follows calculated to gangue-free substance, the modes of decomposition employed being indicated at the heads of the several columns:

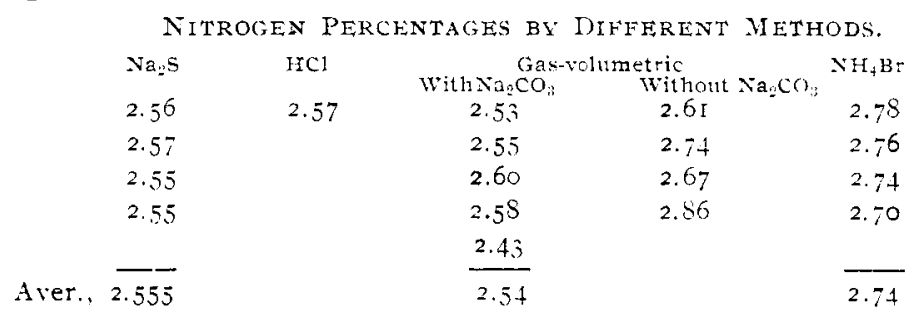

The single determination after solution of the mineral in hydrochloric acid and removal of the mercury as sulphide and of the $\mathrm{SO}_{4}$ as the barium salt, is regarded with conflence, as also those by the sodium sulphide 
method. The greater variation among the results by the gas-volumetric tests with sodium carbonate is to be ascribed to the small amounts of mineral used-0.25-0.5 gram, 一 the uncertainty in the burette readings in the upper section of the instrument and the greater chance for loss or gain during the numerous manipulations. The high results by the ammonium bromide method have been explained above. Those by the gas method without sodium carbonate are not clearly accounted for, but the results obtained in that way were always less satisfactory by reason of the fouling of the pump outlet and of the mercury in the collecting tube by the free chlorine that was formed.

(2) Mercury. Mercury was determined in several ways, almost always in connection with one of the nitrogen determinations: (a) As mercury, by ignition with sodium carbonate and once as in organic combustion of mercury compounds. Most of the determinations were by this method. (b) As mercury, by electrolysis from sodium-sulphide solution. (c) As the sulphide. The last method usually afforded higher and probably truer results than the first.

(3) Chlorine and sulphur. Since slight loss of chlorine and of sulphur as sulphur dioxide almost always resulted when the mineral was heated by itself, these components were deternined in the sodium carbonate employed for the gas-volumetric determination of nitrogen. A greater variation among the few chlorine results for the lighter colored crystals was observed than for the orange-colored ones, which latter afforded excellently agreeing results. But the results for the lighter crystals were in no case so markedly different from the others as to confirm Professor Sachs' conclusion that there was an appreciable chemical difference between the crystals of different shades, and they were in part affected by obvious errors.

(4) Water. None of the water afforded by the mineral is hygroscopic. About one-half comes off at $135^{\circ}-150^{\circ}$, and the total that is obtained by careful heating of the mineral by itself to complete decomposition, using a plug of gold leaf in the exit of the tube, is not clearly in excess of that obtained after the manner of organic combustion with copper oxide preceded by lead chromate and a roll of copper. Some of it comes from the clayey gangue, but most is beyond question given off by the mercury mineral. How much belongs to one and how much to the other it has been impossible to ascertain. The water determinations constitute the least satisfactory portion of the analytical results.

In the different specimens analyzed the gangue ran from 0.75 to 3 per cent. in the dehydrated state, as obtained by ignition. In the full report the many analyses are given both as made and after recalculation to a gangue-free basis for both orange and light colored crystals. We reproduce here only the averaged results for the deeper colored crystals since 
they were in best agreement, repeating that although the light colored crystals afforded greater variations in chlorine and sulphur than the orange ones, this was in part due to obvious errors, and that the means for these constitueuts were slightly higher than for the orange crystals, rather than far lower as found by Sachs. To include them would hardly affect the general average.

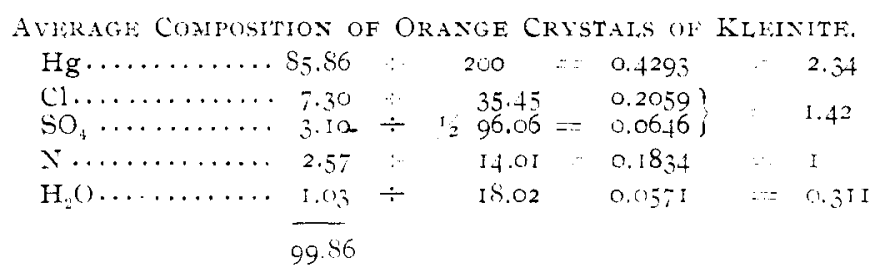

In discussing the auove ratios, it must be borne in mind that the number for water is of doubtful value, so that it can receive little attention. The water cannot exist in large part even as hydroxyl, for that would require an amount of basic oxygen entirely opposed to all the evidence, in which that of summation is not of least import. The ratio shows at once that there is far too little nitrogen for a general formula of the type $\mathrm{NHg}_{2} \mathrm{X} . x \mathrm{H}_{2} \mathrm{O}$, in which $\mathrm{X}$ represents $\mathrm{Ci}$ and $\mathrm{SO}_{4}$. It is even insufficient for the chlorine alone in such a formula, and we are therefore obliged to consider the possibility of the body being a mixture. Calomel as a constituent of such a mixture is excluded from consideration for the reason that but a trace is indicated on dissolving the mineral in warm hydrochloric acid, and this appears to be clerived from the gangue. Mercuric chloricle would seem to be excluded by its solubility in water. As oxychlorides there would naturally be considered first terlinguaite and eglestonite, but both are excluded for the reason that they yield on solution in hydrochloric acid calomel. It remains to assume a mercuric oxychloride and then an oxysulphate, both of which might perhaps be formed simultaneously with $\mathrm{NHg}_{2} \mathrm{Cl} . \mathrm{H}_{2} \mathrm{O}$, from a mercuric solution containing more mercury than is needed by the ammonia present to form a compound of this type. If perchance the oxychloricle were $\mathrm{Hg}_{2} \mathrm{Cl}_{2} \mathrm{O}$ or $\mathrm{HgO} . \mathrm{HgCl}_{2}$, and allowance were made for it on this basis in the ratio above given, the ratio of the residuals would show an oxysulphate witl $\mathrm{Hg}$ to $\mathrm{SO}_{4}$ as 4 to 3.23 and composition nearly $\mathrm{Hg}_{4} \mathrm{O}\left(\mathrm{SO}_{1}\right)_{3}$, or $\mathrm{HgO}$.${ }_{3} \mathrm{HgSO}_{4}$. The calculated amounts of these salts would demand 0.33 per cent. of basic oxygen, an amount that happens to coincide almost exactly with that indicated by the nitrogen determinations according to the ammonium bromide method (p. I 86 ), which as will be remembered gave more than was obtained by other methods. While the excess of ammonia obtained by the ammonium bromide method is with considerable reason believed to be in part due to the action of the aluminous gangue 
on the reagent, calculation shows that it cannot well all have originated thus. If not, the only alternative, assuming that the tests were reasonably correct, is that an oxy-salt or salts of mercury must have given rise to some at least of that excess of ammonia. The chief objection to accepting this alternative is the volume of oxygen corresponding to the required weight percentage, which if wholly given off as oxygen gas on heating the mineral itself ought not to have escaped detection and approximate measurement. Still, it is conceivable that in this method of operating the basic oxygen might not all escape as gas. The evidence as to the presence of a little basic oxygen is conflicting, and further speculation would be profitless in the present state of our knowledge regarding this remarkable mineral. To assume that the nitrogen is very low and should be 2.885 per cent. or exactly equivalent to the chlorine, is opposed by much evidence, including the fact that the sulphate would then be strongly acid.

It is regrettable that the long labor has resulted in nothing more definite than the fixing of this mineral as the first naturally occurring member of the so-called mercury-ammonium compounds and the untenableness of the possibility suggested by Professor Sachs. The question as to the structure of these mercury-ammonium bodies, whether they belong to one or other of the several types that have been suggested for them, is outside the scope of this investigation.

\section{Montroydite.}

Orthorhombic holohedral $: a: b: c=0.6375: 1: 1.1977$ (Schaller). Fifty-six forms observed, forty-five new. Two crystal habits with all intermediate gradations: (I) Prismatic, flexible, dark-red needles, commonly I $1 / 2 \mathrm{~cm}$., occasionally $2 / 2 \mathrm{~cm}$. long, by less than I mm. thick, often partially grayish from what appears to be a thin coating of some other (presumably mercury) mineral, or minute and orange in sereral forms, notably wormlike, and (2), nearly equidimensional crystals of a few millimeters diameter. The larger needles occur also in curiously twisted and curved shapes, the minute orange ones in irregular rounded and loosely coherent masses. There are also hollow, irregularly-shaped and bubble-like formations that in their interior resemble geodes, being lined with or nearly filled with one or both of the above-mentioned types of crystals. A somewhat different form of bubble is found between large calcite crystals, smooth and somewhat glistening exteriorly, gray-black and partially filled with a spongy mass of crystalline material that is commonly very dark in color. Precise descriptions of these and other modes of occurrence are difficult to give in few words.

Color, dark red to yellow-brown or orange-brown. Streak, yellowbrown. Transparent to translucent. Cleavage, perfect $\{$ oro $\}$. Hardness, $2-3$, less than 2 (Moses). Brittle, also sectile, but the long needles 
extremely flexible, can be rolled around a thin rod. Density not determined because of inability to separate completely from free mercury enough for a satisfactory test.

Completely volatile without fusing, yielding in a closed tube a sublimate of mercury only. Slowly blackened by hydrogen sulphide, but not equally over all surfaces.

Since the oxygen as given for montroydite by Professor Moses was assumed by difference, a direct determination was made by dissociating the mineral in vacuo, collecting, measuring and testing the gas evolved. The result was to confirm the identification of Professor Moses.

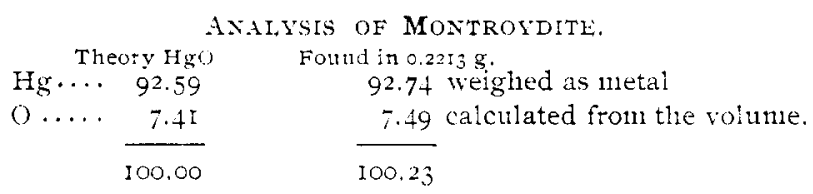

Terlinguaite.

Monoclinic prismatic (holohedral), $a: b: c:=1.6050: 1: 2.0245, \beta=74^{\circ}$ $23^{\prime}$. (Schaller.) Of the one hundred and thirty-three forms observed, one hundred and two are new. Crystals often extended in one direction and also equidimensional. The largest crystal measured $16 \times 4 \times 4 \mathrm{~mm}$, though faces over a centimeter broad are sometimes to be seen. Also occurs in powdery form impregnating the earthy gangue, to judge from the greenish color of some specimens of ore, and perhaps in a similar state admixed with eglestonite, in which case its identification is at least diffcult. Much confusion seems to exist as to the original color of terlinguaite before it has been exposed to light. Moses writes of it as "sulphur-yellow with a slight greenish tinge, very slowly darkening on exposure to an olive green," but Mr. Hartley in reply to our inquiry wrote that the terlinguaite crystals were green ere they were touched by the sunlight, but that most of the terlinguaite occurs as a yellow powder changing to green. Sometines brown crystals are seen and occasionally the green and brown colors appear in the same crystal. When brown they are difficult to distinguish at sight from eglestonite in one of its transitional color stages. Some of our earthy specimens that were yellow at first turned greenish on exposure and presumably contained terlinguaite. Beautiful spots of emerald green reflected light appear when the crystals are exanined with a lens as they occur on the specimen. If at times originally yellow the mineral is not in that state always distinguishable from kleinite, and perhaps not from eglestonite or even from the orange-red form of montroydite.

Streak yellow, turning greenish grey in light. Transparent or nearly so. Luster, brilliaut adamantine. Cleavage, perfect Ior subsectile. Harduess, 2-3. Density, 8.725 (Moses). 
The effect of heating crystals in a closed tube differs somewhat according as this is done slowly or quickly. When quickly done there is violent decrepitation, continuing till the mineral has volatilized, the substance turning red-brown or almost vermilion in color (orange-yellow cold) and much of the resulting powder being projected up on to the sublimate of calomel and mercury above the assay. Eventually there is complete volatilization. With slow heat decrepitation is hardly noticeable. With the first burst of calomel sublimate there appears a little mercury, but then only calomel so long as there is any chlorine left in the residue. Sometimes at the last, when the flame is removed, brilliant short red needles of mercuric oxide form on the warm glass by recombination of some of the mercury vapor and oxygen.

Iu vacuo the color changes of the crystals as the heat increases are more marked, these being, after first appearance of a sublinate, red, black (without loss of luster), red-brown, orange-brown and dull. Before becoming completely orange-brown some faces are olive-greenish. When orange-brown the only visible sublimate is calomel and no trace of oxygen has been evolved. The residue then seems to be mercuric oxide, upon the decomposition of which partial recombination of its constituents occurs, to judge from the deposition on the warm glass near by of a slight orange-brown sublimate.

Hydrogen sulphide blackens the edges of a crystal, but further action is very slow; ammonia blackens only after some time. The second test serves to distinguish the mineral from eglestonite, which is at once blackened by ammonia. This difference in behavior of terlinguaite and eglestonite is in line with their chemical difference, the former being mercuric-mercurous, the latter wholly mercurous. Hydrochloric and nitric acids decompose terlinguaite with separation of calomel. The hydrochloric filtrate yields much bivalent mercury. Cold acetic acid slowly decomposes the mineral when in powder, also with separation of calomel, and in the filtrate hydrochloric acid produces no further precipitate, or but a very faint one. Eglestonite under similar treatment yields a heavy calomel precipitate, the filtrate from which is free from mercury.

Moses' empirical formula was confirmed by analyses in which the oxygen was measured directly and found to be wholly absorbed by phosphorus, thus showing its freedom from nitrogen.

ANALYses of Teringtaite Calculated TO GaNgUe-Fren Substance.

\begin{tabular}{|c|c|c|c|c|c|}
\hline \multicolumn{2}{|c|}{ Theory $\mathrm{Hg}_{2} \mathrm{ClO}$} & I. & II. & III. & Ratio of III. \\
\hline $\mathrm{Hg} \ldots \ldots \ldots \ldots$ & 88.65 & 88.92 & $88.3 \mathrm{I}$ & $88.6 \mathrm{I}^{1}$ & 2.00 \\
\hline $\mathrm{Cl} \ldots \ldots \ldots \ldots \ldots$ & 7.85 & & & 7.83 & 1.00 \\
\hline $0 \ldots \ldots \ldots \ldots$ & 3.50 & & & 3.75 & 1.06 \\
\hline & 100.00 & & & IOO. I9 & \\
\hline
\end{tabular}

I Mean of I and II.

The high oxygen found in III is due probably more to error in meas- 
uring so small a volume as $2.67 \mathrm{cc}$. than to the little montroydite that was present.

The only artificial mercuric-mercurous oxychloride hitherto prepared has the formula of terlinguaite.

\section{Eglestonite.}

Isometric holohedral. Crystals small, equidimensional, usually about and under one millimeter in diameter. They show two habits, one determined by the development of the rhombic dodecahedron and not particularly rich in forms, the other determined by development of the octahedron and with abundant forms. Of the twenty-one forms observed serenteen are new. Whether eglestonite can be distinguished by its color in the mine or soon after remoral therefrom from terlinguaite, with which it is sometimes closely associated, or from kleinite or the orange montroydite, we are unable to say, but from the confusion that existed in the minds of those who sent us our specimens it seems that it must be at least difficult to do so. The first specimens received were dark brownish and of dodecahedral habit, others were of octahedral habit and light brownish yellow. These last became darker in time. If sufficiently exposed the crystals turn black, but without losing their luster, as noticed by Moses. Streak yellow, turning black. Luster adamantine to resinous. Transparent to translucent. Brittle. Cleavage lacking. Fracture uneven and apparently sometimes conchoidal. Hardness, 2-3 (Moses). Density, 8.237 (Moses); not determined by us for the same reason as with terlinguaite, diffculty of freeing perfectly from mercury enough material for a satisfactory test.

When heated in a closed tube, compo:ts itself in almost every respect like terlinguaite. The residue, after expulsion of the calomel, seems to be mercuric oxide as with terlinguaite, formed in this case, however, from mercurous oxide at the expense of half the mercury of the latter, a reaction which accords with the observation that no oxygen escapes till all the calomel and some mercury have sublimed.

Hydrogen sulphide acts very much as upon terlinguaite and ammonia blackens at once, the latter reaction serving as a ready distinguishing test between the tro minerals. Hydrochloric and nitric acids decompose it with separation of calomel. The hydrochloric acid filtrate contaitus no mercury. Cold dilute acetic acid acts more quickly on the powder of eglestonite than on that of terlinguaite, calomel is left and from the filtrate much more can be obtained by hydrochloric acid. The final filtrate is free from mercury. These tests, confirmed by the analysis, show clearly the mercurous nature of the compound, the first anthentic instance of a mercurous oxychloride, native or artificial.

Analysis did not confirm the empirical formula $\mathrm{Hg}_{6} \mathrm{Cl}_{3} \mathrm{O}_{2}$, deduced from ' Fischer, T., and von Wartenbers. II., Chem.-Ztg. 29. 30S (I005). 
J. S. McCord's analyses in the paper by Professor Moses, a formula which, in fact, is invalidated by the qualitative data above given, since it calls for mercuric as well as mercurous mercury. The analyses were made in the main as for terlinguaite, with the exception that the chlorine and mercury in the sublimate were each time determined, the separation being effected by sodium hydroxide, and the little mercury that goes into solution with the chlorine by this operation being recovered. Calculated to gangue-free substance the results were as follows :

Analysis of Eglestonite CALCULATEd to Gangue-Free Substance.

\begin{tabular}{|c|c|c|c|c|c|c|c|}
\hline $\mathrm{Hg} . .$. & $\begin{array}{l}\text { Theory } \\
\mathrm{Hg}_{4} \mathrm{Cl}_{2} \mathrm{O} \\
90.2 \mathrm{I}\end{array}$ & $\begin{array}{c}\text { I. } \\
0.195 \mathrm{~g} . \\
88.33\end{array}$ & $\begin{array}{l}\text { At. ratio } \\
\text { 4. I I }\end{array}$ & $\begin{array}{l}\text { II. } \\
0.1008 \mathrm{~g} . \\
88.94\end{array}$ & $\begin{array}{c}\text { At. ratio } \\
3 . S_{7}\end{array}$ & $\begin{array}{l}\text { III. } \\
0 . \text { II } 8 \mathrm{~g} . \\
89.73\end{array}$ & $\begin{array}{l}\text { At. ratic } \\
3.99\end{array}$ \\
\hline $\mathrm{Cl} \ldots \ldots$ & 7.99 & 8.32 & 2.18 & 8.23 & 2.02 & 8.1 2 & 2.03 \\
\hline $0 \ldots \ldots$ & I. 80 & 1.72 & I & $1.84^{1}$ & I & I. 80 & I \\
\hline & 100.00 & 98.37 & & 99.01 & & 99.65 & \\
\hline
\end{tabular}

In all cases the mercury is probably low, and calomel was present to a slight extent in sample I at least. It is quite probable that the oxygen was less accurately determined than the chlorine, but the effect of low mercury and the presence of calomel are better brought out by the ratio based on oxygen than on chlorine as unity. The formula plainly indicated is $\mathrm{Hg}_{4} \mathrm{Cl}_{2} \mathrm{O}$, or $\mathrm{Hg}_{2} \mathrm{O} .2 \mathrm{HgCl}$, one that is in full agreement with the qualitative behavior of the mineral. The variations in the analytical data reported by Moses are so wide that the excellent agreement of his averages with the formula $\mathrm{Hg}_{3} \mathrm{Cl}_{3} \mathrm{O}_{2}$ can be $\mathrm{d} \mathrm{n}$ uet oa lyo balancing of large errors. The oxygen values of his table were indirectly determined and are affected by the errors involved in other determinations, which inspection shows were large.

The ammonium bromide method, used with kleinite for determining nitrogen, might probably be employed successfully with eglestonite and terlinguaite and any other compounds of similar kind for the indirect but very accurate determination of the basic oxygen in them.

Two specimens of what was supposed to be eglestonite were analyzed, but with results indicative of a mixture of terlinguaite with calomel, though the appearance of both was decidedly against this. Possibly they represent a new species.

\section{Calomel.}

The crystals of calomel often reach a large size, some being I $1 / 2 \mathrm{~cm}$. in diameter. They are very rich in forms, a total of thirty having been observed, of which ten are new. The crystals are frequently twinned, twinning plane $e\{$ OI $\}$. The formula for calomel being well established, no chemical work was done on this mineral.

\section{Native Mercury.}

Native mercury occurs abundantly on nearly all of the specimens, ex${ }^{1}$ I.90 by loss in weight of ign. tube. 
cept those of kleinite, on which we have not seen it. It is usually present as globular irregular masses associated directly with the other minerals. Globules often project from small cavities on the surfaces of crystals of terlinguaite, eglestonite and montroydite, and are sometimes to be seen in the interior of crystals of terlinguaite and montroydite, notably the latter. While much of it is in the form of a fairly pure liquid, a good deal is mixed with powdery oxychlorides as a sort of stiff paste having a gray or greenish color and irregularly associated with the plainly crystallized oxychlorides and montroydite. The proximate determination of this gray or greenish mass is almost impossible. Some of the mass has a yellowish, almost metallic sheen. which is perhaps largely an iridescent effect.

\section{Summary.}

Kleinite, as announced in 1905 , belongs to the so-called mercury ammonium compounds, but no probable formula can be deduced from the analyses. It may be a mixture of a mercury-ammonium chloride in great preponderance, $\mathrm{NHg_{2 }} \mathrm{Cl}_{1} \mathrm{I}_{3} \mathrm{H}_{2} \mathrm{O}$, with an oxychloride and sulphate or oxysulphate of mercury.

Terlinguaite is a mercuric-mercurous oxychloride, $\mathrm{HgO} . \mathrm{HgCl}$, the formula of Moses being confrmed and the mixed nature ascertained by tests.

Eglestonite is a mercurous oxychloride, $\mathrm{Hg}_{2} \mathrm{O} .2 \mathrm{HgCl}$, the first authentic instance of such a compound, either artificial or native, and not $\mathrm{Hg}_{6} \mathrm{Cl}_{3} \mathrm{O}_{2}$, as believed by Moses.

Montroydite is mercuric oxide, as supposed by Moses, and proven now by direct determination of its oxygen content.

I,ABORATORY $\tau$. S. GEOLOGICAL STRVEY,

Washington, D. C., July.

[CONtribution from the Havemeyer laboratories, Columpia UniVERSITY, NO. I39.].

SOME NEW DOUBLE PHOSPHATES OF CHROMIUM. ${ }^{1}$

BY LOYTS I. CORHN.

Received Ju11e ro. 1907.

In attempting to prepare a double phosphate of chromium under the conditions of acidity already described in the formation of the iron and aluminum salts, ${ }^{2}$ negative results were obtained; no precipitate was formed even when an extremely large excess of diammonium phosphate was added. When, however, the acidity was diminished, a precipitate was readily obtained.

The chromium solution employed was prepared by treating a little more than twenty grams of Kahlbaum's chromium hydroxide with 45.2

${ }^{i}$ Read at the April meeting of the $\mathrm{X}$. Y. Section of the Anter. Chem. Society.

'This Journal 29, 5 . 